\title{
Policy Agenda Setting of "Coal to Gas" in China Based on Multiple-Streams Theory Analysis Framework: A Case Study
}

\author{
Tianhong $\mathrm{Gao}^{1, *}$ and Jia Guo ${ }^{1}$ \\ ${ }^{1}$ School of Government, Beijing Normal University, HaiDian District, Beijing 100875, P. R. China \\ *Email: shannon2019@163.com
}

\begin{abstract}
Air pollution control is related to environmental quality and personal life safety, related to economic and socially sustainable development. To solve the long-term problem of haze in northern China, the "coal to gas" policy in China has been ups and downs. Exploring the change of China's "coal to gas" policy is crucial to understand the development of environmental policy in China. This paper used the extended framework analysis of Multiple-streams Theory to take the policy adjustment of "coal to gas" in Hebei Province from 2012 to 2018 as a case, and found that the policy agenda setting of "coal to gas" is a cross-type, and different policy agenda models complement each other in the process of multi-agent game. Media promote the mutual influence between the streams and the final trend. The three streams set in the policy agenda of "coal to gas" influence each other or even blend in the flow, and flow in stages, reflecting the characteristics of mutual penetration and interaction of multi-stage and multi-stream.
\end{abstract}

Keywords: coal to gas; Multiple-stream Theory; policy agenda; Multi-stage and Multi-stream Analysis Model

\section{INTRODUCTION}

Since the reform and opening-up, China's economy has been developing steadily. However, environmental protection is facing more and more severe challenges, and the contradiction between China's economic and social development and the constraints of resources and environment have become increasingly prominent. Over the years, the Chinese government has taken a firm resolve to tackle air pollution, not only to reduce the air pollution index, but also to take action in the energy sector, win the "blue sky defense war", and promote environmental protection and development.

As a transitional means for clean and renewable energy to replace traditional energy comprehensively, the "coal to gas" policy has become a reasonable choice, which plays an important role in improving China's energy structure. The Law of the People's Republic of China on The Prevention and Control of Air Pollution, amended as early as 2000 , mentioned that the governments of key cities for the prevention and control of air pollution can stop using highly polluting fuels and switch to clean energy sources such as natural gas within a time limit. After long-term governance exploration and engineering preparation, the Ministry of Finance, the Ministry of Housing and UrbanRural Development, the Ministry of Environmental Protection and National Energy Administration jointly issued Notice on the implementation of the central financial support for the northern winter clean heating pilot work in May 2017. In September of the same year, these four national government departments issued guidance to promote the " $2+26$ " cities in Beijing, Tianjin, Hebei and surrounding areas to focus on "coal to gas", "coal to electricity" and renewable energy heating. In December 2017, the State Council issued Letter on the comprehensive management of scattered coal to ensure that the masses warm winter work to the " $2+26$ " cities around Beijing, Tianjin and Hebei. The policy focus shifted to "safeguarding the masses to live in the winter as the first principle". Subsequently, the state and local governments quickly issued adjustment policies, and the policy discourse shifted to "determining changes by air" and "implementing transformation in strict accordance with the plan and steps".

There are few studies on the policy agenda and dynamic changes of "coal to gas" policy in China, and most scholars study the necessity of coal to gas policy implementation from the problem level and policy level. As an important energy policy in China, why can the "coal to gas" policy be fully promoted since 2017 but quickly adjusted to "gasbased reform" in the formal and comprehensive coal ban period of that year? What stages have the agenda setting of the "coal to gas" policy gone through? Eight cities in Hebei Province are included in the first batch of implementation of the winter clean heating plan in the northern region. This paper selects the "coal to gas" policy process in Hebei Province as an example is enough to explore the changes and logic behind China's "coal to gas" policy. 


\section{LITERATURE REVIEW AND ANALYSIS FRAMEWORK}

\subsection{Policy Agenda Setting}

Western policy scientists study the policy agenda earlier, Lasswell first proposed the concept of "Policy Process" [3], the policy process is divided into seven stages, each stage has independent research value. After the policy process theory has been continuously developed by Anderson, Bardach, Dye, and other scholars, it has provided rich results for the study of various stages of the policy process. Kingdon[1] proposed that "Agenda refers to the cataloging of issues that government officials and their closely related non-government personnel pay close attention to at any given time", that is, the policy is a problem that government decision-makers think needs to solve. Dr.Severin concluded that the government, the media and the public interact with each other and decide what is an important event, which is called "Agenda Settings". The setting of policy agenda is the starting point of public policy, social problems may become public problems, but whether social problems can become public problems depends on whether the problem can enter the government's decision-making agenda[2].

When borrowing the Western policy agenda model, scholars in China have noticed the impact of China's special national conditions on agenda setting. For example, Ning[6] revealed the "Up and Down Decision Model" of the relationship between the decision-making level and the public. Professor Wang, a representative scholar of policy agenda setting in China, divides the agenda into three categories: media agenda, public agenda and policy agenda[7], fully demonstrates the characteristics of policy agenda setting in the Chinese context. In recent years, many scholars have paid attention to the influence of media on the policy agenda, they have studied the relationship between the media agenda, the public agenda, and the policy agenda from the background of the network era, explored the media trigger mode and the focus event activation mode[8]-[10].

\subsection{The Multi-stage and Multi-stream Analysis Model}

In the book Agenda, Options and Public Policy published in 1984, American policy scientist and politician John Kingdon[1] proposed the multiple-stream theory based on the decision model of Cohen et al., aiming at the policy agenda setting and options. This theory proposed the concepts of multiple-stream, coupling, policy window and policy entrepreneurs. Multiple-stream is divided into three streams: problem stream, policy stream, and political stream. The three streams flow independently, and only when they meet at a specific time point can they jointly put the issue on the policy agenda. The classical multiple- stream theory model has a variety of expansion forms, which provides a useful analytical framework for the study of complex and subtle issues in agenda setting and decision-making process

Due to the differences between China and the United States in the political system, policy environment and decisionmaking mechanism[11], most Chinese scholars will adjust the original framework according to the Chinese situation when using the multiple-stream theory to analyze local cases. Based on Kingdon's multiple-stream theory analysis framework, combined with the existing multiple-streams theory expansion framework, especially the multi-stage and multi-stream analysis model improved by $\mathrm{Ye}$ and Wang[12]. Kingdon's metaphor of "streams", "water" and "coupling" has inspired scholars' endless imagination. They believe that the streams have a "multi-stage" nature, which is prominently manifested in the gradualness of the policy process. When entering the next stage, the "flow" of the original problem flow, political flow and policy flow will decrease, and the "solute" will also change.

To sum up, the policy agenda setting is the first step to attach importance to and solve the problems of personal concern, and it is worth exploring how to make a social problem rise to the field of government decision-making. At present, there is a vacancy in the academic research field on the agenda setting and dynamic adjustment of the "coal to gas" policy, and there is also a lack of a comprehensive review of the national "coal to gas" policy. From the perspective of the multi-stage and multi-stream analysis model, this paper uses the process tracking method, according to the timeline to sort out the policy of coal to gas from 2000 policy documents clearly put forward the policy text of "coal to gas" to "gas-based reform", takes the "coal to gas" policy of Hebei Province as an example to sort out the process of China's "coal to gas" policy going into the field of public policy and its subsequent policy changes in recent years, and analyzes the key forces behind the comprehensive introduction and readjustment of the "coal to gas" policy in detail.

\section{THE CASE ANALYSIS}

\subsection{A Summary of the Case of "Coal to Gas" Policy in Hebei Province}

The residents in Hebei Province of north China used to burn coal to keep warm in the winter, the winter climate and atmospheric circulation not conducive to the spread of pollutants. Also, it is rich in steel and grain, the industrial structure means the industrial emissions and easy to form more air pollutants such as straw burning.

From the perspective of discourse, the word "coal to gas" first appeared in the policy document. In the Air Pollution Prevention Law of the People's Republic of China issued by the State Council in April 2000, it was mentioned that units and individuals in key cities for air pollution 
prevention and control should stop burning high-pollution fuels and switch to natural gas, liquefied petroleum gas, electricity or other clean energy within the time limit stipulated by the local government. Here, it was mentioned that the scope of the specification was "key cities for air pollution prevention and control" and only one "switch to natural gas" appeared in the policy text.

Before 2012, there was no content related to "coal to gas" reform in the official policy text basically, let alone relevant policies for "coal to gas" reform. However, since 2012, the key changes have taken place in the "coal to gas" policy. There are positive discourses such as "promotion" and "strengthening" in the policy discourse, indicating that the "coal to gas" project has attracted the attention of the government. In 2016, at this time, the "coal to gas" project has been advancing rapidly, has begun to promote the implementation of industrial coal to gas projects in qualified parks. Hebei Province orderly implementation of the rural "coal to gas" project. In March 2017, the Ministry of Environmental Protection and other four ministries jointly issued The 2017 air pollution prevention and control work plan of Beijing-Tianjin-Hebei and its surrounding areas with the government of Beijing, Tianjin, Hebei, Henan, Shandong, Shanxi, and officially designated " $2+26$ " cities, among which eight cities in Hebei Province are listed. At the end of 2017, Hebei Province issued an emergency Emergency Plan for Natural Gas Peaking Winter in Hebei Province (2017-2018), with the policy focus shifting to "safeguarding the masses to live through the winter as the first principle". Subsequently, the State and various ministries and commissions in Hebei Province issued adjustment policies, insisting on the principle of "gas-based reform", and "implementing transformation in strict accordance with the plan and steps".

In terms of policy quantity (as shown in Fig. 1), in just three years from 2012 to 2014, the policy on coal to gas has increased year by year. In 2014 , it reached a small peak of relevant policy release. The state and the Hebei local government issued a total of eight relevant policies, indicating that the long-silence policy on "coal to gas" has resurrected and quickly converged into the first policy window. After realizing the goal of setting the policy agenda of coal to gas, the "flow rate" in the streams has decreased and the "flow rate" has slowed down. However, in 2016, the number of policies surged to 13, and in 2017 it continued to maintain an increasing momentum of 13 . It can be seen that some events drifted into the stream at this

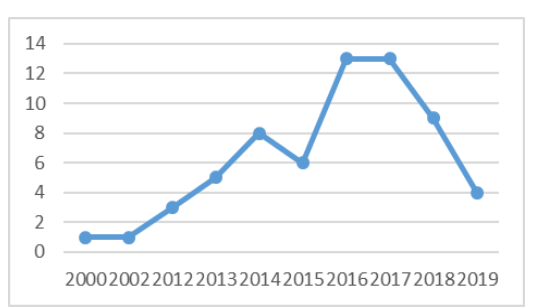

Figure 1. Number of "coal to gas" policies issued by the central government and Hebei provincial government time, making the "water" surge and the "flow rate" accelerated, scouring the soil originally precipitated, and the "solute" was different from the first stage.

\subsection{The Multi-stage and Multi-stream Analysis of The "Coal to Gas" Policy in Hebei Province}

\subsubsection{Problem stream}

\subsubsection{Warning of social indicators}

First of all, Hebei Province has long occupied a place among the cities with heavy air quality detection pollution. According to the Monthly Air Quality Report released by the China National Environmental Monitoring Station, since 2013, cities in Hebei Province have been listed in the top 10 of cities with heavy air pollution at least $50 \%$ of the time. Secondly, there are fewer days when the air is fine and the haze lasts longer. Shijiazhuang, Tangshan and Xingtai of Hebei Province, had zero air quality days in 2013, compared with 31 days in 2015, 15 days in 2015 and 12 days in 2015, according to the Chinese Academy of Sciences. According to various data, the air pollution level in Hebei Province reached its peak in 2013 in the first stage, and the haze problem was not exactly solved in the subsequent years of governance.

\subsubsection{Warning of social indicators}

Chinanews.com is one of the most importantly original content providers of Chinese news. We searched domestic reports on haze through it in the decade from 2009 to 2019 , and draws the table of the number of Chinese media reports on the phenomenon of haze, as shown in Fig. 2.

It can be seen that the number of reports from 2009 to 2012 is relatively small, and the annual increase is relatively small. In 2013, the haze a rapidly growing number of reports, unprecedented Numbers of reports, media reports of a large number of offers high-frequency feedback, influence the public attention to the problem, the annual keyword as "smog" also illustrates the governance of the

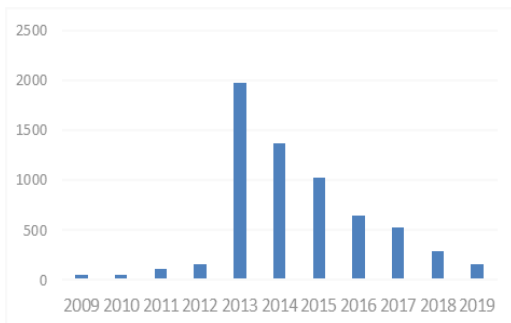

Figure 2. Number of reports on smog on Chinanews from 2009 to 2019 
problem is directly under various strong focus, enough to make the use of clean energy this root problem on the policy agenda of the source of the problem.

\subsubsection{Catalysis of focal events}

In February 2015, Chai Jing, a well-known journalist, released a self-funded documentary entitled "Chai Jing Haze Investigation: Under the Dome", in which she revealed the "truth" of haze to the public through field investigation. Through the proliferation of new media networks, the broadcast of the documentary caused great controversy and repercussions. As an important policy entrepreneur in the first stage, Chai used her special journalist status and resources to promote the revision of the Atmospheric Pollution Prevention and Control Law. In-depth interviews, detailed data, and emotional copywriting in the investigation symbolized the vague and scattered reality. Traditional policy agenda setting is dominated by rational factors, but in the network society, the policy agenda setting contains more diversified factors and tends to be irrational[13]. Chai also sent her results to the Legal Working Committee of the National People's Congress.

However, just over a year after the policy window for the first phase was opened, the flow of problems subsided. The comprehensive policy of replacing coal with gas in Hebei Province in 2017 deviated greatly from the expected effect, evolved into an unexpected livelihood issue, and aroused people's serious dissatisfaction with the dissemination of online media. According to media reports, some primary schools are not heating in time. The Education Department of Hebei Province dealt with the incident seriously. It shows the change in government attitudes.

\subsubsection{Policy stream}

"If a problem has a solution attached to it, the likelihood that it will be on the decision-making agenda increases dramatically", Says Kingdon. In the process of setting and changing the "coal to gas" policy agenda, many government officials, academic experts, news media practitioners, energy policy practitioners and others formed a policy community to discuss how to improve the air pollution caused by coal combustion combined with the actual situation in China and the use of clean energy abroad. They "soften" mainly through academic works, news reports and interviews.

In the first stage of the policy proposal on haze control, due to the professional nature of energy and environmental protection, scholars and energy policy practitioners are more active among the actors involved. For example, the scholars represented by Meng and Sun[14]. The second stage involves the protection of people's livelihood, and the influence of policies expressed by the public and media actors appears, forming an "interactive mode" of two-way communication with the authorities. For example, on December 5, 2017, the People's Daily reported an editorial, citing the report of the 19th National Congress of the CPC that "Improving people's well-being is the fundamental goal of development". On the one hand, the media reflects the people's livelihood, on the other hand, it also expresses the views of the government. As a platform for discourse expression, it is not only a field where policy entrepreneurs soften, but also a place where the government responds to external pressure and alleviates external pressure.

\subsubsection{Political stream}

\section{$\underline{\text { 3.2.3.1. Public sentiment }}$}

Public sentiment is a collective attitude and opinion formed by individual value judgment. With the continuous development of the internet and the influence of the new media environment, the dissemination of information is more and more convenient, and the influence of information is more and more important to society and politics. Under the influence of many factors such as the discussion of Internet new media, information disclosure, the awakening of civil rights awareness and improvement of environmental awareness, the public requires the government to solve the problem of air pollution that threatens people's basic right to life and health. China is a country of democratic centralism, and The People's Congress System is the regime organization form of Chinese people's democratic dictatorship, as well as an important way to reflect the public sentiment.

At the "two sessions" in 2012, Wang Yusuo, a member of the Standing Committee of the National Committee of the Chinese People's Political Consultative Conference (CPPCC), focused his attention on the "coal to gas" project, and proposed to vigorously promote the application of energy supply technology with the best energy efficiency in the field of urban energy supply. Li Yanqun, a deputy to the National People's Congress in 2014, and Yang Chongyong, a deputy to the National People's Congress in 2017, both mentioned the promotion of the "coal to gas" policy in their reports, hoping for policy support from the state.

\subsubsection{The political orientation of the ruling party}

In this case, the key department personnel adjustment related to the cause and time node of "coal to gas" transformation is related to the core leadership. Therefore, the two factors are analyzed together and called "the political orientation of the ruling party", which is mainly reflected in the attitude change of the core leadership that can influence the policy direction[15].

China is a country where the party and government are inseparable. The personnel adjustment of key departments will have a gradual impact on political orientation, especially the transfer of the position of "top leader". The 
policy tendency of party leaders will be transmitted to local party organizations from level to level.

Since the 18th National Congress of the CPC, the new generation of leadership with $\mathrm{Xi}$ Jinping at its core has advocated green development and met the people's needs not only for material and cultural but also for ecological and environmental needs such as fresh air and clean water. This leadership push is also reflected in the second stage of the gas shortage period. The Chinese government quickly adjust decision priority, because the communist party of China will take "safeguard the people's happiness" as its mission, so when the governmental implementation of coal to gas firm faith and the deep faith of "safeguard the people's livelihood" conflict, coal to natural gas will be priority adjustment policy rhythm to ensure the people's basic life safeguard.

\subsubsection{Geographical political factors}

As a province around the capital circle, The BeijingTianjin-Hebei region is China's capital economic circle, including Beijing, Tianjin and 11 prefecture-level cities in Hebei Province. Iron and steel industry in Hebei Province from the planned economy period is the important force pull the local economy in Hebei, if to protect the ecology, clean atmosphere environment, shutting down polluting factories, control of industrial development is necessary, but in Hebei Province are faced with the problem is that its industrial structure adjustment pace is not independent, but passively with control the rhythm of Beijing. So it is imperative that the Beijing-Tianjin-Hebei region as an organic whole of furthering "coal to gas" policy. Therefore, once the national leaders allocate their attention to the "coal to gas" policy, it will help accelerate the implementation of the "coal to gas" policy on the government agenda, and realize the comprehensive implementation in urban and rural areas from the beginning of the second phase.

\subsubsection{Tree streams coupling}

The first stage is dominated by the streams and political stream power of three streams, gather three origins are favorably for "coal to gas" policy into the policy agenda setting direction, Forming a coupling that facilitates the opening of the first policy window. Hebei provincial government issued Notice on the implementation of a longterm mechanism for stable natural gas supply in May 2014, according to this notification and the situation of the province.

At this stage, the "water" flows down like a waterfall, but at the end of the first stage, the problem stream has already flowed into the flat riverbed. At this time, the "flow rate" slows down and the amount of "water" decreases, showing the trend of slow flow. At this point, because of poor "coal to gas" policy implementation effect, cause the public discussion and winter heating topic media continue to report, as a storm bring new vitality for flow problems, poured into the new thought, forms a "stream erosion" on the original policy. Problem stream under the event catalytic torrent surging again, from the social indicators haze has not solved, but media reports, attention problem stream from the first stage of the atmospheric pollution problems to safeguard the people's livelihood problems. The political stream with the greatest potential energy in the first stage flows successfully into the second stage, and the different "solutes" in the political flow react with each other. Finally, three streams succeed again made the window of the new stage of policy in coupling.

\section{CONCLUSION}

This paper discusses the process of the policy agenda setting and policy change in combination with China's "coal to gas" policy. First, the "coal to gas" policy agenda setting presents cross-cutting, and different policy agenda models complement each other in the process of the multiagent game. In the multiple actors' interaction and contradiction collision process, the government sometimes difficult to rational coordinate the interests of the complex. For example, in the first stage, the three streams in the cooperation of policy entrepreneurs successfully open the window of policy, but in the second stage, the problem stream and political stream have changed, and under the great potential energy of political stream, the window of policy in the second stage has been opened. Thus in the process of gradual policy change in response to the new challenge, government should quick start agenda with government commitments and pro-people government image mold, forming the institutionalization and diversity of responsibility appraisal mechanism[16]. Second, the media play an important role in guiding national sentiment and promoting the focus event plan in the adjustment of "coal to gas" policy. The media not only played a role in the case event line, but also mixed various elements in the "garbage can", such as complex reality, policy concepts and public perception, promoting the mutual influence and final direction between three streams. Third, the three streams, in the agenda of China's "coal to gas" policy, influence each other or even blend and flow in stages. In the second phase, the composition of the external environment in problem stream and political stream is changed, political attention from atmospheric pollution transfer to the problem of the people's livelihood. Different forces or power, or game, or concessions between and within different streams in different stages reflect the characteristics of multi-stage and multi-stream mutual penetration and interaction.

The limitation of this paper is that the multiple-stream theory has not been further modified to fully adapt to the object of study in this paper. So the adaptability of the study needs to be strengthened. Besides, the "coal to gas" policy is a complex practical problem, and it is still in constant adjustment and trial, this study needs further exploration and improvement. 


\section{REFERENCES}

[1] John W. Kingdon.Agenda, Options and Public Policy (second edition), Beijing: Renmin University of China Press, 2004.

[2] Severin, Werner Joseph, and James W. Tankard. Communication theories: Origins, methods, and uses in the mass media, New York: Longman, 1997.

[3] Lasswell, Harold D. "The Decision Process: Seven Categories of Functional Analysis," The Decision Process: Seven Categories of Functional Analysis 1956: 1-22. Print.

[4] Dye, Thomas R., and Thomas R. Dye. Understanding public policy, Englewood Cliffs, NJ: Prentice Hall, 1992.

[5] Cohen, M. D. and March, J. G., \& Olsen, J. P.. “A garbage can model of organizational choice," Administrative Science Quarterly, 1972, 17(1), 1-25. DOI: https://doi.org/10.2307/2392088.

[6] Ning, S. Public Policy, Higher Education Press, 2001. (In Chinese)

[7] Wang, SG. "Chinese public policy agenda setting model," Chinese Social Science, vol.5, pp.86-99+207, 2006. (In Chinese)

[8] Chen, JE and Wang, GH. "Research on policy Agenda Setting Mechanism in the Internet Era," China Administration, vol.1, pp.28-33, 2013. (In Chinese)

[9] Chen, GJ. "Research on the influence of network media on policy agenda setting: from the perspective of stress mode," Journal of ZheJiang provincial party school,vol.1, pp.117-123, 2012. (In Chinese)

[10] Deng, Z and Meng, QG. "We-media agenda setting: a new path for the formation of public policy," Journal of public administration, vol.2, pp.14-22+153, 2016. (In Chinese)

[11] Guo, C and Chen, EL. "Multi-stream theoretical interpretation of China's network education policy changes," Education research, vol.5, pp.151-159, 2019. (In Chinese)

[12] Ye,L and Wang, YQ. "Policy process and innovation mechanism of grassroots intelligent supervision: a case study of market supervision departments at the district level in eastern coastal Cities," Chinese Administration, vol.8, pp.35-40, 2019. (In Chinese)
[13] Winkel G and Leipold S. "Demolishing dikes: multiple streams and policy discourse analysis," Policy Studies Journal, vol.1, pp.108-129, 2016. DOI: $10.1111 /$ psj.12136

[14] Meng, YD and Sun, HL. "Discussion on the development of 'coal to gas' in Beijing-Tianjin-Hebei region," International petroleum economy, vol.11, pp.84-90+112, 2014. (In Chinese)

[15] Zhao, J and Xue, L. "Responsive agenda-setting model: an analysis based on a case study of China's public policy transformation," Research in Political Science, vol.3, pp.42-51+126, 2017. (In Chinese)

[16] Gong, X. "Analysis on the trigger mechanism of policy agenda setting under the 'external pressure mode': an interpretation of the mechanism for the emergence and resolution of public events," Journal of Sichuan Provincial Party School, vol.2, 37-41, 2012. (In Chinese)

[17] Yu, YD and Yao, N. "An exploration of the analytical framework of policy agenda setting and on the motivation of this round of institutional reform of the state council," Chinese Administration, vol.7, pp.2731, 2013. (In Chinese)

[18] Howlett, Michael, Allan Mcconnell, and Anthony Perl. "Streams and stages: reconciling Kingdon and policy process theory," European Journal of Political Research, vol.5, pp.419-434, 2015. DOI: 10.1111/14756765.12064

[19] Wang, LZ and Li, YX. "Analysis of policy Changes and their Multiple sources in the context of media convergence: taking the policy changes from 'one-child' to 'comprehensive two-child' as an example," Journal of Nanjing University (Philosophy, Humanities, Social Sciences), vol.5, pp.98-110+3, 2008. (In Chinese)

[20] Chen, L., Zhao J and Xue L. "A choice or a compromise?-An explanatory framework and consensus decision-making model for China's policy process in the transition period," Management World, vol.8, pp.59-72+187, 2010. (In Chinese)

[21] Yang, LH and Yang, WJ. "Air pollution conflict resolution mechanism in China: a multi-method hybrid Study," China Administration, vol.11, pp.118-127, 2017. (In Chinese) 